\title{
A NEW METHOD FOR DETERMINING THE RATE OF SULPHATION OF STORAGE-BATTERY PLATES.
}

By G. W. Vinal and L. M. Ritchie.

ABSTRACT.

This paper describes experiments which have been made to develop a speedy and accurate method for measuring the effect of impurities in storage-battery electrolyte. In the present paper the fundamental theory of the method and measurements of the rate of sulphation of the plates in pure acid is given.

Because of the inaccuracies of the method previously used and the time required to complete the experiments it was decided to determine the effect of impurities in terms of the rate of the reaction taking place at the plates. This may be accurately determined in a short time by successive weighings of the plates immersed in solutions which are maintained at constant temperature. The plates were suspended in the electrolytes from the arm of a sensitive balance. By this arrangement it is possible to weigh each plate without exposing it to the air. The reaction at the negative plate may be both chemical and electrochemical. The measurements show that the former predominate. The rate of sulphation of the negative plates increased as the concentration of the electrolyte and the temperature were increased. The rate of sulphation of the positive plates is much less than for the negative plates. Corrections for the buoyancy of the electrolyte are necessary. It is possible to compute from the electrochemical equivalents the number of ampere-hours of discharge occurring as local action.

CONTENTS.

Page.

I. Introduction.

II7

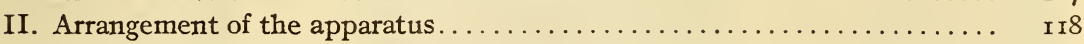

III. Experimental results. ................ II9

\section{INTRODUCTION.}

This investigation was undertaken to establish if possible a speedy and accurate method for the measurement of the effect of impurities in storage-battery electrolytes. Preliminary experiments in which small cells were "poisoned" by the addition of the substances to be studied showed that accurate and consistent results were difficult to obtain. The capacity of the negative plates is ordinarily greater than that of the positives, and the effect of such impurities as affect the negative plate is therefore masked, in part at least, when determinations of the capacity are made. It is difficult also to insulate the small cells so perfectly that leakage current during the periods of standing will not affect the measured capacity. It is often necessary to allow $13059^{\circ}-22$ 
several weeks to elapse in order to determine the loss in capacity resulting from the impurities which are added. Because of the inaccuracies of this method and the time required it was decided to determine the effect of the impurities in terms of the rate of the reactions taking place at the plates. This may be accurately determined in a short time by successive weighings of the plates immersed in solutions which are maintained at a constant temperature.

In the present paper it is desired to present only the fundamental theory of the method and the results which have been obtained for the rate of sulphation of positive and negative plates in solutions of pure sulphuric acid of various concentrations. According to Dolezalek ${ }^{1}$ measurements of the rate of self-discharge of the plates in varying concentrations of the electrolytes have not been made. The method here described affords a simple and accurate means of obtaining this information. The changes taking place at the negative plate are most readily studied by this method, but the interpretation of the results obtained on positive plates presents greater difficulties. The method is not immediately applicable to the study of such impurities as serve as oxygen carriers between the plates of different polarity. In a subsequent paper the effects of impurities will be discussed.

\section{ARRANGEMENT OF THE APPARATUS.}

The general arrangement of the apparatus is shown in Figure $\mathrm{I}$. Twenty-four plates were suspended by glass hooks and entirely immersed in the electrolytes, which were contained in six rectangular glass jars, four plates to each jar. These jars were carried on a revolving frame in the thermostat bath which permitted the plates in any jar to be brought to a point directly underneath the left-hand arm of the balance. The balance was mounted on a marble slab over the thermostat tank as shown in the illustration. By this arrangement it was possible to weigh each plate while immersed and without exposing it to the air. The thermostat tank was filled with water to within I inch of the top of the jars. The temperature of the water could be controlled by a thermoregulator at any desired point within the range 20 to $40^{\circ} \mathrm{C}$. The variation of the temperature of the water from a fixed point was within $0.01^{\circ}$. The water was stirred continuously. Each jar was provided with a wood cover impregnated with parafin. 
Technologic Papers of the Bureau of Standards, Vol. 17.

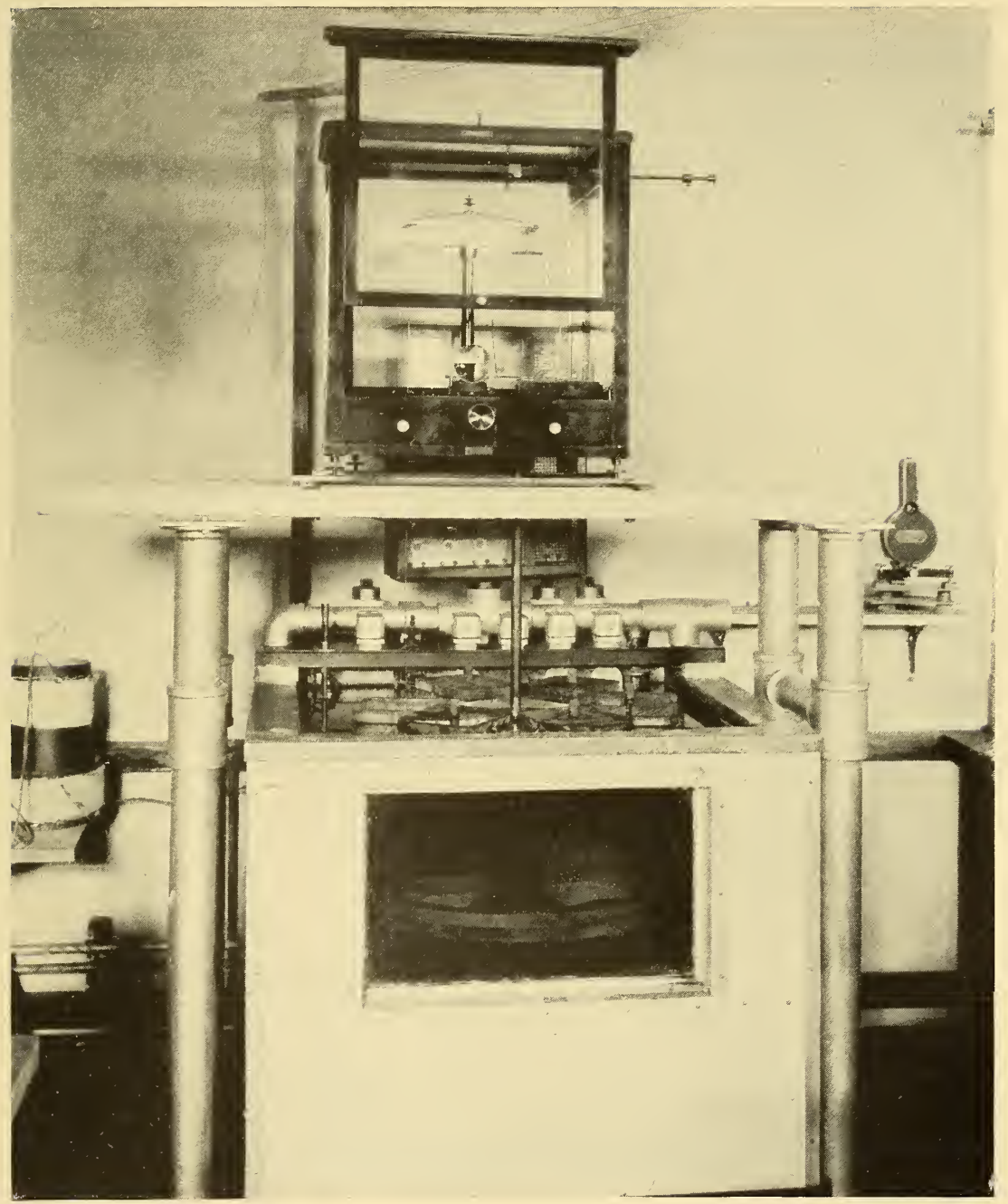

FIG. I.-Apparatus for determining the rate of sulphation of storage-battery plates. 

The plates selected for the experiments were those made for starting and lighting batteries by two manufacturers. Small sizes of plates were selected to avoid overloading the balance, which was of high quality, having a nominal capacity of $200 \mathrm{~g}$. The plates of maker A were $5 \frac{5}{8}$ by $4 \frac{\mathrm{T}}{8}$ by $\frac{3}{32}$ inch; those of maker B were approximately $5 \frac{5}{8}$ by $4 \frac{3}{4}$ by $\frac{3}{32}$ inch.

To adapt these plates to the conditions of our experiments the lug was cut off and burned on again in the middle of the top edge in order to balance the plate when suspended in the liquid. Two holes were drilled in the lug. One of these was used for the glass hook which suspended the plate from the balance during weighings and the other for a second glass hook which supported the plates when weighings were not in progress.

\section{EXPERIMENTAL RESULTS.}

Weighings of the plates were made daily and the results computed as the increase of weight per hour. Three sets of weighings extending over a period of 48 hours were sufficient to give two determinations of the rate of change in weight of the plates. These two determinations in nearly all cases were in good agreement. Four weighings at $25^{\circ} \mathrm{C}$. were made giving three determinations of the change in weight. The mean of these is given in the table below.

Since the weighings were made in the electrolyte, a buoyancy correction was necessary. This correction has been calculated on the assumption that the materials have the following densities:

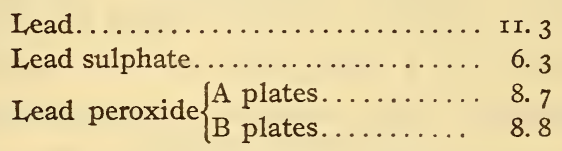

Since the values for the density of lead peroxide found in the literature differ widely, determinations of the density of the active materials of the positive plates in the fully charged condition have been made by Mr. Peffer at the Bureau of Standards with the results given above. Analysis of the active materials by $\mathrm{Mr}$. Altrup shows 97 per cent lead peroxide in the positives of each manufacturer, 97 per cent lead in the negatives of manufacturer $A$, and 91.5 per cent lead in the negatives of manufacturer $B$. The expanders in the negatives were carbon in each case. The buoyancy corrections are applied to a small difference of two weighings, and hence a slight error in the density of either the solutions or the active materials produces a negligible error in the final result. $13059^{\circ}-22-2$ 
The densities of the solutions were determined directly by the use of calibrated hydrometers.

The chemical reactions during discharge at the plates are generally assumed to be represented by the equations:

$$
\begin{aligned}
\mathrm{Pb}+\mathrm{SO}_{4} & =\mathrm{PbSO}_{4} \text { negative plate. } \\
\mathrm{PbO}_{2}+\mathrm{H}_{2}+\mathrm{H}_{2} \mathrm{SO}_{4} & =\mathrm{PbSO}_{4}+2 \mathrm{H}_{2} \mathrm{O} \text { positive plate. }
\end{aligned}
$$

Since the molecular weight of lead is 207.20 and of lead sulphate 303.26 , the gain in weight during the transformation of $\mathrm{I} \mathrm{mol}$ of lead to lead sulphate is $96.06 \mathrm{~g}$; and the relative gain in weight $\frac{96.06}{207.20}$ times the weight of lead acted upon. There is, of course, a large amount of lead which does not take part in the reaction and decreases the sensibility of the weighings, but in spite of this fact and the heavy damping resulting from the viscosity of the electrolytes the balance was sufficiently sensitive to permit an accuracy of a few tenths of a milligram to be obtained.

From the rate of change in weight of the plates the equivalent loss in ampere-hour capacity can be computed. The valence is 2 and hence a gain in weight of the negative plate of $96.06 \mathrm{~g}$ is equivalent to $2 \times 96,500$ coulombs. From this the change in weight is computed to be $1.79 \mathrm{~g}$ per ampere-hour.

Both chemical and electrochemical reactions are possible at the negative plate, but the former are probably predominant over the latter during self-discharge. This is indicated by the results for the A plates in I.I 50 and I.400 acid. The gain in weight per hour in the stronger acid is 23 times that in the more dilute. The change in potential of a lead plate as the concentration of the electrolyte is changed from I.I 50 to I.400 specific gravity acid is less than o. I volt according to the measurements of Gladstone and Hibbert. $^{2}$ The resistivity of the more concentrated electrolyte is higher than for the I.I 50 specific gravity electrolyte. On the basis of Ohm's law, therefore, this marked increase in the extent of the reaction can not be readily accounted for as an electrochemical reaction.

The measurements on the negative plates at $25^{\circ} \mathrm{C}$. are given in Table I. Each figure is the mean of six observations (three measurements on each of two plates). Buoyancy corrections have been made.

${ }^{2}$ J. Inst. Elec. Eng. (British), 21, p. 430; 1892. 
TABLE 1.-Gain in Weight, Grams per Hour, of Negative Plates in Solutions at $25^{\circ}$ C., Saturated and Unsaturated with Lead Sulphate.

\begin{tabular}{|c|c|c|c|c|}
\hline \multirow{3}{*}{ Specific gravity $\frac{25^{\circ}}{25^{\circ}}$. } & \multicolumn{4}{|c|}{ Gain in weight for plates of- } \\
\hline & \multicolumn{2}{|c|}{ Manufacturer A. } & \multicolumn{2}{|c|}{ Manufacturer B. } \\
\hline & $\begin{array}{l}\text { Saturated } \\
\text { solution. }\end{array}$ & $\begin{array}{c}\text { Unsaturated } \\
\text { solution. }\end{array}$ & $\begin{array}{l}\text { Saturated } \\
\text { solution. }\end{array}$ & $\begin{array}{l}\text { Unsaturated } \\
\text { solution. }\end{array}$ \\
\hline 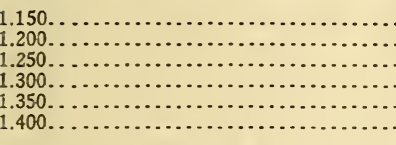 & $\begin{array}{l}0.0022 \\
.0026 \\
.0036 \\
.0060 \\
.0151 \\
.0460\end{array}$ & $\begin{array}{r}0.0031 \\
.0071 \\
.0098 \\
.0115 \\
.0270 \\
.0480\end{array}$ & $\begin{array}{r}0.0048 \\
.0118 \\
.0178 \\
.0283 \\
.0385 \\
.0906\end{array}$ & $\begin{array}{l}0.0058 \\
.0120 \\
.0290 \\
.0394 \\
.0559 \\
.0960\end{array}$ \\
\hline
\end{tabular}

These results show that the rate of sulphation is decreased appreciably in the saturated solution of concentrations corresponding to those ordinarily used in storage batteries. The solutions were saturated with chemically pure lead sulphate when hot and were allowed to cool before the plates were immersed. The electrolyte in a lead storage battery is ordinarily saturated with lead sulphate although the electrolyte is initially a solution of pure sulphuric acid. In these experiments the ratio of the mass of acid to the mass of the plates was purposely made so large that saturation could not occur in as short a time as is ordinarily the case. Each jar contained 4.5 liters of solution and four negative plates.

The rate of sulphation decreased as time progressed. This is especially noticeable in the case of the plates of manufacturer $B$ in the unsaturated solutions of higher concentration as is shown in Table 2.

TABLE 2.-Decrease in Rate of Sulphation with Time, Negative Plates in Unsaturated Solution.

[Mieasurements on plates of manufacturer B.]

\begin{tabular}{|c|c|c|c|c|c|c|}
\hline \multirow{2}{*}{ Date. } & \multicolumn{6}{|c|}{ Gain in weight, grams per hour, for each of sis concentrations- } \\
\hline & 1.150 & 1.200 & 1.250 & 1.300 & 1.350 & 1.400 \\
\hline $\begin{array}{l}\text { Feb. } 19 \ldots \ldots \ldots \\
\text { Feb. } 20 \ldots \ldots \\
\text { Feb. } 21 \ldots \ldots \\
\text { Feb. } 22 \ldots \ldots \\
\text { Feb. } 25 \ldots \ldots \\
\text { Feb. } 27 \ldots \ldots \\
\end{array}$ & $\begin{array}{l}0.0059 \\
.0053 \\
.0061 \\
.0050 \\
.0052 \\
.0053\end{array}$ & $\begin{array}{r}0.0132 \\
.0110 \\
.0121 \\
.0118 \\
.0110 \\
.0113\end{array}$ & $\begin{array}{l}0.0304 \\
.0289 \\
.0275 \\
.0260 \\
.0247 \\
.0236\end{array}$ & $\begin{array}{l}0.0416 \\
.0414 \\
.0352 \\
.0369 \\
.0359 \\
.0332\end{array}$ & $\begin{array}{l}0.0574 \\
.0560 \\
.0535 \\
.0484 \\
.0498 \\
.0470\end{array}$ & $\begin{array}{r}0.0976 \\
.0964 \\
.0942 \\
.0818 \\
.0819 \\
.0769\end{array}$ \\
\hline
\end{tabular}


It can easily be computed that the capacity of the plates would be exhausted in a relatively short time if the initial rate of sulphation were to continue indefinitely. The decrease in the rate of sulphation is probably to be attributed to the protection which the lead sulphate affords to the underlying active material and also to the increasing amount of lead sulphate present in the solutions which were initially unsaturated. The effect of the presence of lead sulphate in decreasing the rate of sulphation of the plates has been shown in Table $I$, but the effect of saturating the solution in holding the rate of sulphation constant for a few days during which measurements of the effect of impurities can be made is of fundamental importance in establishing the validity of this method. This is made clear in Table 3 , in which comparative results for the plates of manufacturer $\mathrm{A}$ are given for a period of three days for both the saturated and unsaturated solutions. The results with the minus signs express the decrease in rate of sulphation during this time. Inconsistent results are to be observed for the solutions of I.I 50 and I.200 specific gravity, but this is not surprising, since these solutions are in the region of the minimum solubility for lead sulphate according to the curve given by Dolezalek. ${ }^{3}$ In this region there can be but little distinction drawn between saturated and unsaturated solutions. The measurements made on the plates of manufacturer B were not as consistent as those for manufacturer A because of a tendency for the active material to scale off, which produced an error in the results.

TABLE 3.-Effect of Saturating the Electrolyte with Lead Sulphate on the Constancy of the Rate of Sulphation over a Period of Three Days.

[The minus signs indicate a decrease in the rate and plus signs an increase. Plates of manufacturer A.]

\begin{tabular}{c|c|c|c|c|c|c}
\hline & \multicolumn{3}{|c|}{ Change in the rate of sulphation, grams per hour, in solutions at $25^{\circ}$ C., } \\
for each of six concentrations-
\end{tabular}

The effect of temperature on the rate of sulphation is important. In Table 4 are given the measurements made on the negative plates of both manufacturers when the solutions were maintained at constant temperatures of 22,25 , and $30^{\circ} \mathrm{C}$. The increase in the rate of sulphation from 22 to $25^{\circ} \mathrm{C}$. is proportionately greater than from 25 to $30^{\circ} \mathrm{C}$.

\footnotetext{
3 Theory of the Lead Accumulator, p. I45.
} 
TABLE 4.-Effect of Temperature on the Rate of Sulphation of Negative Plates.

\begin{tabular}{|c|c|c|c|c|c|c|}
\hline \multirow{3}{*}{ Specific gravity $\frac{25^{\circ}}{25^{\circ}}$. } & \multicolumn{6}{|c|}{ Gain in weight, grams per hour, saturated solutions, for plates of- } \\
\hline & \multicolumn{3}{|c|}{ Manufacturer $B$ at- } & \multicolumn{3}{|c|}{ Manufacturer $\mathrm{A}$ at- } \\
\hline & $22^{\circ} \mathrm{C}$. & $25^{\circ} \mathrm{C}$. & $30^{\circ} \mathrm{C}$. & $22^{\circ} \mathrm{C}$ & $25^{\circ} \mathrm{C}$. & $30^{\circ} \mathrm{C}$. \\
\hline $\begin{array}{l}1.150 \\
1.200 \\
1.250 \\
1.300 \\
1.350 \\
1.400\end{array}$ & $\begin{array}{l}0.0031 \\
.0073 \\
.0111 \\
.0183 \\
.0270 \\
.0614\end{array}$ & $\begin{array}{l}0.0048 \\
.0118 \\
.0178 \\
.0283 \\
.0385 \\
.0906\end{array}$ & $\begin{array}{l}0.0056 \\
.0118 \\
.0196 \\
.0325 \\
.0420 \\
.1027\end{array}$ & $\begin{array}{l}0.0012 \\
.0016 \\
.0028 \\
.0046 \\
.0122 \\
.0350\end{array}$ & $\begin{array}{l}0.0022 \\
.0026 \\
.0036 \\
.0060 \\
.0151 \\
.0460\end{array}$ & $\begin{array}{l}0.0022 \\
.0027 \\
.0051 \\
.0082 \\
.0196 \\
.0544\end{array}$ \\
\hline
\end{tabular}

Local action at the positive plate is essentially electrochemical, resulting from the difference in potential between the oxide and the lead-antimony alloy of the grid. Metallic impurities are not precipitated by the oxide, and Dolezalek and Finckh ${ }^{4}$ have stated that no solubility of the peroxide in solutions of the specific gravities ordinarily used in storage batteries can be detected. The reaction at the positive plate in these experiments is therefore to be regarded as the general expression for the discharge of a cell, with the qualification that the negative electrode may be lead or lead-antimony alloy depending on the construction of the plate.

$$
\mathrm{PbO}_{2}+\mathrm{Pb}+2 \mathrm{H}_{2} \mathrm{SO}_{4}=2 \mathrm{PbSO}_{4}+2 \mathrm{H}_{2} \mathrm{O}
$$

The lead sulphate formed appears on both the peroxide and the grid.

The gain in weight of the positive plates is not as simply related to the total amount of sulphate formed as in the case of the negatives. The sulphate which forms on the grid or the underlying lead is equal to $96.06 \mathrm{~g}$ for $2 \times 96,500$ coulombs but the change in weight of the positive plates because of the formation of sulphate on the peroxide is $64.06 \mathrm{~g}$ for the same quantity of electricity. The difference is accounted for by the formation of $2 \mathrm{mols}$ of water at the peroxide. This means that I60.I $2 \mathrm{~g}$ of sulphate would be formed on the positive plate if the quantity of electricity flowing were $2 \times 96,500$ coulombs. The ampere-hour equivalent for the gain in weight resulting from local action is, therefore, $2.99 \mathrm{~g}$ for each ampere-hour. The experimental results for the positive plates in solutions of varying concentration at $25^{\circ} \mathrm{C}$. are given in Table 5 for solutions saturated and unsaturated with lead sulphate. 
TABLE 5.-Gain in Weight, Grams per Hour, of Positive Plates in Solutions at $25^{\circ}$ C. Saturated and Unsaturated with Lead Sulphate.

\begin{tabular}{|c|c|c|c|c|}
\hline \multirow{3}{*}{ Specific gravity $\frac{25^{\circ}}{25^{\circ}}$. } & \multicolumn{4}{|c|}{ Gain in weight for plates of- } \\
\hline & \multicolumn{2}{|c|}{ Manufacturer A. } & \multicolumn{2}{|c|}{ Manutacturer B. } \\
\hline & $\begin{array}{l}\text { Saturated } \\
\text { solution. }\end{array}$ & $\begin{array}{l}\text { Unsatu- } \\
\text { rated } \\
\text { solution. }\end{array}$ & $\begin{array}{l}\text { Saturated } \\
\text { solution. }\end{array}$ & $\begin{array}{l}\text { Unsatu- } \\
\text { rated } \\
\text { solution. }\end{array}$ \\
\hline 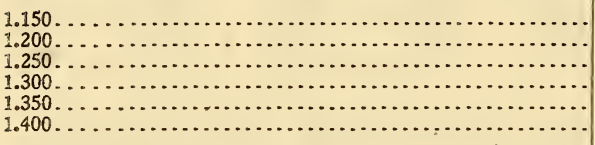 & $\begin{array}{r}0.0128 \\
.0121 \\
.0069 \\
.0053 \\
.0050 \\
.0047\end{array}$ & $\begin{array}{l}0.0111 \\
.0096 \\
.0060 \\
.0022 \\
.0019 \\
.0031\end{array}$ & $\begin{array}{r}0.0077 \\
.0077 \\
.0047 \\
.0050 \\
.0048 \\
.0049\end{array}$ & $\begin{array}{l}0.0138 \\
.0090 \\
.0051 \\
.0061 \\
.0062 \\
.0088\end{array}$ \\
\hline
\end{tabular}

It will be observed from the results given in Table 5 that the gain in weight of the positive plates decreases as the concentration of the solution increases. This suggests that the plates contained some soluble constituent, the solubility of which increased as the concentration increased, but the data which are available on the solubility of lead peroxide and lead oxide fail to offer an explanation. In the solutions which were saturated the gain in weight of the plates was more for manufacturer A but less for manufacturer $B$ than in the unsaturated solutions. The differences in behavior may be attributed to the different methods used in preparing the paste for these plates, but no exact explanation can be given.

WASHIngton, August i4, 1922. 